\title{
NUMERICAL EVALUATION OF RUIN PROBABILITIES FOR A FINITE PERIOD*
}

\author{
OLOF THORIN \\ AND \\ NiLS Wikstad \\ Stockholm
}

\section{SUMMARY}

In this paper the authors remind of the known formulas for the double Laplace-Stieltjes transforms of the ruin probabilities $\psi(u, t)$, where $u$ is the initial risk reserve and $t$ stands for the operational time, in the case of independent interoccurence times and claim amounts such that the interoccurrence times are identically distributed $K(t), t \geq 0, K(0)=0$, and the claim amounts are iclentically distributed $P(y),-\infty<y<\infty$. For some cases, where $\mathrm{I}-P(y)$ and $\mathrm{I}-K(t)$ are exponential polynomials, numerical inversions of the said Laplace-Stieltjes transforms are made for a selection of $u$ - and $t$-values in combination with safety loadings of various sizes and signs. Moreover, some values are given when $\mathrm{I}-P(y)$ or $\mathrm{I}-K(t)$ are of Pareto type and comparisons are made with the results when the Pareto distributions are approximated by suitable exponential polynomials.

\section{INTRODUCTION}

The risk model considered is as follows:

The interclaim times $t_{1}, t_{2}, \ldots$ and the claim amounts $Y_{1}, Y_{2}, \ldots$ are assumed to be mutually independent stochastic variables such that the $t_{j}$ 's are identically distributed $K(t), t \geq 0, K(0)=0$, and the $Y_{j}$ 's are identically distributed $P(y),-\infty<y<\infty$. This model is due to Sparre Andersen who presented it at the New York Congress, 1957. An important particular case is the Poisson process generated by the choice $K(t)=\mathrm{I}-e^{-\beta t}$ where we without real loss of generality may take $\beta=\mathrm{I}$.

In the following we mostly restrict the distribution functions $K(t)$ and $P(y)$ to belong to the classes

* Seminar presentation at the I9th International Congress of Actuaries, Oslo, 1972. 


$$
\begin{array}{ll}
P(y)=\int_{\int_{0}^{\infty}\left(1-e^{-\alpha y}\right) d V(\alpha),} & y \geqq 0 \\
0, & y<0 \\
K(t)=\int_{0}^{\infty}\left(\mathrm{I}-e^{-\beta t}\right) d W(\beta), & t \geqq 0 \\
0, & t<0
\end{array}
$$

respectively where $V(\alpha)$ and $W(\beta)$ are distribution functions such that $V(0)=W(0)=0$.

The class (I) was considered by Hilary L. Seal in his paper in TSA I969: "Simulation of the ruin potential of nonlife insurance companies". The following particular cases were pointed out by him:

i) $V(\alpha)=\varepsilon(\alpha-\mathrm{I})$ giving $P(y)=\mathrm{I}-e^{-y}, y \geqq 0$

ii) $V^{\prime}(\alpha)=\frac{\gamma^{\alpha}}{\Gamma(\alpha)} \alpha^{\alpha-1} e^{-\gamma \alpha}, \alpha>$ o, i.e. a $\Gamma$-distribution giving $P(y)=\mathrm{I}-\left(\mathrm{I}+\frac{y}{\gamma}\right)^{-x}, x>0, \gamma>0, y \geqq$, i.e. a Pareto distribution.

Immediate generalizations of (3) and (4) are

iii) $V(\alpha)=\sum_{j=1}^{m} a_{j} \varepsilon\left(\alpha-\alpha_{j}\right), a_{j}>0, \sum_{j=1}^{m} a_{j}=I$

$$
\text { giving } P(y)=\mathrm{I}-\sum_{j=1}^{m} a_{j} e^{-\alpha_{j} y}, \quad y \geqq 0
$$

iv) $V^{\prime}(\alpha)>0$ and continuous for $\quad \alpha>0$

Of course, it is easy to construct intermediate forms between (5) and (6). A case related to (6) though not belonging to it is:

$$
\begin{gathered}
V(\alpha)=0, \alpha \leqq \frac{\mathrm{I}}{b}, b>\mathrm{I} \\
V^{\prime}(\alpha)=\frac{\sin \frac{\pi}{b}}{\pi} \alpha^{-1}(b \alpha-\mathrm{I})^{-1 / b}, \alpha>\frac{\mathrm{I}}{b}
\end{gathered}
$$


i.e. a Pareto like distribution, giving

$$
P(y)=\frac{\mathrm{I}}{\Gamma\left(\frac{\mathrm{I}}{b}\right)} \int_{0}^{\frac{y}{b}} x^{\frac{1}{b}-1} e^{-x} d x
$$

i.e. a $\Gamma$-distribution with parameter $\mathrm{I} / b<\mathrm{I}$.

(This $P(y)$ was considered by Bohman and Grandell \& Segerdahl in papers to appear in Skandinavisk Aktuarietidskrift.)

The case (4) i.e. $P(y)=\mathrm{I}-\left(\mathrm{I}+\frac{y}{\gamma}\right)^{-x}$

has the mean value one if we choose $\gamma=x-\mathrm{I}, x>\mathrm{I}$, thus

$$
P(y)=\mathrm{I}-\left(\mathrm{I}+\frac{y}{x-\mathrm{I}}\right)^{-x}
$$

It is interesting-though trivial-to note that, if we here let $x \rightarrow \infty$, we get

$$
P(y) \rightarrow \mathrm{I}-e^{-y},
$$

that is, the simple exponential distribution is obtained as a limiting case of a Pareto distribution. Of course, this fact is not surprising since the "dangerousness" of the Pareto distribution tends to die out when $x$ becomes very large. (Usually one defines a Pareto distribution by

$$
P(x)= \begin{cases}I-\left(\frac{x}{x_{0}}\right)^{-x} & x \geqq x_{0} \\ 0 & x<x_{0}\end{cases}
$$

If so, we must apply a simple translation before the limiting process. Indeed letting $x=x_{0}+y, y \geq 0$ we get

$$
P\left(x_{0}+y\right)= \begin{cases}\mathrm{I}-\left(\mathrm{I}+\frac{y}{x_{0}}\right)^{-\varkappa} & y \geqq 0 \\ 0 & y<0 .)\end{cases}
$$

However, generalizing the above observation of the simple exponential distribution as a limiting case of a Pareto distribution, it is easy to see that we may choose $V^{\prime}(\alpha)$ in (6) such that we get a distribution function $P(y)$ which closely approximates an arbitrary 
member of (5). Conversely, it is obvious that an arbitrary member of the class (I) may be arbitrarily well (in the sense of weak convergence of probability laws) approximated by members of (5).

What we now have said about the class (I) is, mutatis mutandis, true for the class (2) of interclaim time distributions.

From these observations the following conjecture seems natural. Once we have mastered the numerical solution of the ruin problem

for

$$
\left\{\begin{array}{l}
P(y)=\mathrm{I}-\sum_{j=1}^{m} a_{j} e^{-\alpha_{j} y} \\
K(t)=\mathrm{I}-\sum_{j=1}^{n} b_{j} e^{-\beta_{j} y}
\end{array}\right.
$$

then it is not too difficult to go further to the numerical solution of the ruin problem for

$$
\left\{\begin{array}{l}
P(y)=\int_{0}^{\infty}\left(\mathrm{I}-e^{-\alpha y}\right) d V(\alpha) \\
K(t)=\int_{0}^{\infty}\left(\mathrm{I}-e^{-\beta t}\right) d W(\beta)
\end{array}\right.
$$

where $V(\alpha)$ and $W(\beta)$ are not both just staircase functions.

Two lines of approach offer themselves. The first one means that we develop the formulas for (9) in a similar manner as for (8) and then, as far as possible, use the same numerical tools as for (8). The second approach would mean that we approximate the members of (9) by suitable members of (8) and use the ruin probabilities for the latter as approximations of the ruin probabilities for the former. However, if we use the second approach we must be aware that the asymptotic behaviors of the ruin probabilities may be entirely different from the ones obtained by the first approach (See section 5).

2. The Formula apPaRatUS FOR THE RUIN PROBLEM IN CASE THE MODEL PRESENTED AT THE OUTSET OF THE INTRODUCTION IS USED 2.I Generalities(See Thorin: Astin Bulletin VI: I and 2 or Skandinavisk Aktuarietidskrift I970: I-2 and I97I: I-2, 3-4.)

\section{Notations}

$\psi(u)=\psi(u, \infty)=$ ruin probability for an infinite period $\psi(u, t)=$ ruin probability for a finite period, $t, \psi(u, 0)=0$ $u=$ initial risk reserve 
$c=$ gross risk premium per unit of time $(c>0)$

$\bar{\psi}(u, z)=\int_{0}^{\infty} e^{z t} d_{t} \psi(u, t), u \geqq 0, \operatorname{Re}(z) \leqq 0 ; \bar{\psi}(u, z)=0, u<0$

$\psi(u)=\bar{\psi}(u, 0)$

$\bar{\varphi}(s, z)=\mathrm{I}-\int_{0-}^{\infty} e^{s u} d u \bar{\psi}(u, z), \operatorname{Re}(s) \leqq 0 \operatorname{Re}(z)<0$

$A(s, z)=\exp \left[\int_{0+}^{\infty} e^{s u} d_{u} M(u, z)+\frac{1}{2} \Delta M(0, z)\right], \operatorname{Re}(s) \leqq 0$,

$\operatorname{Re}(z)<0$

$B(s, z)=\exp \left[-\int_{-\infty}^{0-} e^{s u} d_{u} M(u, z)-\frac{1}{2} \Delta M(0, z)\right], R e(s) \geqq 0$,

$\operatorname{Re}(z)<0$

where

$M(x, z)=\sum_{n=1}^{\infty}(\mathrm{I} / n) \int_{0}^{\infty} e^{z v}\left(P^{n *}(x+c v)-\mathrm{I}\right) d K^{n *}(v)$

$\Delta M(0, z)=M(0+, z)-M(0-, z)$. (In the cases treated in this paper we have $\Delta M(0, z)=0$.)

With these notations we may write down the following fundamental formula [Note that I - $\bar{\varphi}(s, z)$ is the double LaplaceStieltjes tran: "orm of $\psi(u, t)]$

$$
\varphi(s, z)=\frac{A(s, z)}{A(0, z)}, \operatorname{Re}(s) \leqq 0, \operatorname{Re}(z)<0
$$

By continuity we also get $\bar{\varphi}(s, 0)$ [Note that $\mathrm{I}-\bar{\varphi}(s, 0)$ is the simple Laplace-Stieltjes transform of $\psi(u)=\bar{\psi}(u, 0)]$.

From formula (IO) it is, in principle, possible to get $\psi(u, t)$ by two successive inversions. However, for the classes of distribution functions characterized by (8) and (9) it is, in general, possible to perform the innermost inversion analytically to such an extent that the outer inversion is the only one which must be performed by an inversion algorithm.

2.2 Simplifications if $P(y)=\mathrm{I}-\sum_{j=1}^{m} a_{j} e^{-\alpha, y}$ but $K(t)$ general

In this case (see Thorin: Skandinavisk Aktuarietidskrift I97I: I-2) we have the simple formula 


$$
A(s, z)=\prod_{j=1}^{m} \frac{s-\alpha_{j}}{s-s_{2 j}(z)}, \operatorname{Re}(z) \leqq 0
$$

where $s_{2 j}(z), j=\mathrm{I}, \ldots, m$ denote the $m$ roots in the right halfplane of the equation

$$
k(z-c s) p(s)=\mathbf{I} .
$$

Here

$$
\begin{aligned}
& k(z)=\int_{0}^{\infty} e^{z t} d K(t), \\
& p(s)=\int_{0}^{\infty} e^{s y} d P(y)=\sum_{j=1}^{m} \frac{a_{\jmath}}{\mathrm{I}-s / \alpha_{j}}
\end{aligned}
$$

Herefrom we get, by expanding $A(s, z) / A(\mathrm{o}, z)$ in partial fractions, that

$$
\bar{\psi}(u, z)=\sum_{j=1}^{m} g_{j}(z) e^{-u s_{2 j}(z)}
$$

where

$$
g_{j}(z)=\frac{\prod_{\substack { v-1 \\
\begin{subarray}{c}{v-1 \\
v \neq 1{ v - 1 \\
\begin{subarray} { c } { v - 1 \\
v \neq 1 } }\end{subarray}}^{m}\left(\mathrm{I}-s_{2 j}(z) / \alpha_{v}\right)}{\left.\prod_{2 j}(z) / s_{2 v}(z)\right)}, j=\mathrm{I}, \ldots, m
$$

An equivalent formula for $g_{j}(z)$ is

$g_{j}(z)=$

$$
=\frac{B\left[s_{2 j}(z), z\right]}{A(0, z)\left[k\left(z-c s_{2 j}(z)\right) p^{\prime}\left(s_{2 j}(z)\right)-c k^{\prime}\left(z-c s_{2 j}(z)\right) p\left(s_{2 j}(z)\right)\right] s_{2 j}(z)},
$$

Note that if $K(t)=\mathrm{I}-\sum_{j=1}^{n} b_{j} e^{-\beta_{j} t}$, we have $k(z)=\sum_{v-1}^{n} \frac{b_{v}}{\mathrm{I}-\left(z / \beta_{v}\right)}$, and the $s_{2 j}(z)$ 's may be found as the $m$ roots in the right halfplane 
of a polynomial equation of the $(m+n): t h$ degree. Note also that in this case

$$
\begin{gathered}
B(s, z)=\prod_{j=1}^{n} \frac{c s-c s_{1 j}(z)}{\beta_{j}+c s-z} \\
A(0, z)=\prod_{j=1}^{n} \frac{\alpha_{j}}{s_{2 j}(z)}=\frac{\prod_{j-1}^{n} \frac{c s_{1 j}(z)}{z-\beta_{j}}}{I-k(z)}
\end{gathered}
$$

where $s_{1 j}(z), j=\mathrm{I}, \ldots, n$, are the $n$ roots in the left halfplane of $\mathbf{I}-k(z-c s) p(s)=0$.

2.3 The ruin formulas if $P(y)=I-\int_{0}^{\infty} e^{-\alpha y} d V(\alpha)$ where $V^{\prime}(\alpha)$ is strictly positive and continuous for $\alpha>0$, but $K(t)$ general

First, we observe that

$$
p(s)=\int_{0}^{\infty} \frac{\alpha d V(\alpha)}{\alpha-s} \text { which represents a Stieltjes transform. }
$$

Known properties of this transform (see Widder: The Laplace Transform, Princeton I946) ensure that $p(s)$ is regular and analytic in the entire $s$-plane if we exclude the non-negative real axis. If we denote the boundary values of $p(s)$ on the two sides of the positive real axis by $p^{+}(x)$ and $p^{-}(x)$ we have $p^{+}(x)-p^{-}(x)=$ $2 \pi i x V^{\prime}(x)$ for almost all $x>0$. Thus $\operatorname{Im} p^{+}(x)=\pi x V^{\prime}(x)$.

As a generalization of formula (I2) we get-provided certain rather mild conditions on $p(s)$ and $k(z)$-the following formula

$$
\begin{gathered}
\bar{\psi}(u, z)= \\
=\frac{\mathrm{I}}{A(0, z)} \int_{0}^{\infty} \frac{B(x, z) V^{\prime}(x) e^{-x u} d x}{k(z-c x)\left[\left(\frac{\mathrm{I}}{k(z-c x)}-\operatorname{Re} p^{+}(x)\right)^{2}+\left(\operatorname{Im} p^{+}(x)\right)^{2}\right]}+ \\
+\underset{j}{\Sigma} g_{j}(z) e^{-u s_{2 j}(z)}
\end{gathered}
$$

where $s_{2 j}(z)$ are the roots in the right halfplane excluding the 
positive real axis of the equation $\mathrm{I}-k(z-c s) p(s)=0$. The said roots constitute at most a countable set. Here

$g_{j}(z)=$

$=\frac{B\left(s_{2 j}(z), z\right)}{A(0, z)\left[k\left(z-c s_{2 j}(z)\right) p^{\prime}\left(s_{2 j}(z)\right)-c k^{\prime}\left(z-c s_{2 j}(z)\right) p\left(s_{2 j}(z)\right)\right] s_{2 j}(z)}$

Note that for $z$ negative real there are no $s_{2 j}(z)$ 's so in this case only the integral in (IY) appears. This is also true for a subregion of the left $z$-halfplane enclosing the negative real axis. Sometimes this subregion coincides with the entire left $z$-halfplane. We shall meet such cases in our numerical examples. Note also that for $z$ negative real the denominator of the integrand cannot vanish for $x>0$ since $\operatorname{Im} p^{+}(x)=\pi x V^{\prime}(x)>0$. For a general $z$, however, the denominator sometimes vanishes. In these cases a certain caution is needed. Generally speaking, the vanishing denominator indicates that the actual $z$ lies on a curve in the $z$-plane such that the crossing of it either entails the generation of a new term in the $\Sigma$-expression of (I7) or entails the suppression of such a term depending on in which direction the crossing is made.

\subsection{Numerical observations}

Of course, for numerical purposes the formula (I 7 ) is only manageable when we have simple expressions for $B(s, z)$ and $A(0, z)$. Since this is the case when

$$
K(t)=\mathrm{I}-\sum_{1-1}^{m} b_{j} e^{\beta_{j} t}
$$

as formulas (I5) and (I6) show we restrict ourselves to such $K(t)$ 's when we exploit formula (I7).

However, the formula (I2) may be used even if $K(t)$ has a more general appearance, but then we must restrict $P(y)$ to the form

$$
\mathrm{I}-\sum_{j-1}^{m} a_{j} e^{-\alpha, y} \text {. }
$$

In particular, for $P(y)=\mathrm{I}-e^{-y}$ the formula (I2) gives

$$
\Psi(u, z)=\left(\mathrm{I}-s_{2}(z)\right) e^{-u s_{2}(z)}
$$

irrespective of the shape of $K(t)$. (Needless to say, the value of $s_{2}(z)$ depends on $K(t)$.) 
Note the following simple formula

$$
\Psi(0, z)=\mathrm{I}-\frac{\mathrm{I}}{A(0, z)}
$$

which may be used as a check formula. In particular it is useful when the formula (I 7 ) is applied. (In the case, not treated here, when both $K(t)$ and $P(y)$ are discontinuous it is advisable to use the following modified formula

$$
\left.\Psi(0, z)=\mathrm{I}-\frac{e^{1 / 2 \Delta M(0, z)}}{A(0, z)} \cdot\right)
$$

3. Approximation of a member of the class (I) NOt belonging TO THE CLASS (5) BY A SUITABLE MEMBER OF THE CLASS (5)

For numerical purposes it seems advisable not to use more than five terms in the approximant from the class (5). We then have at most Io parameters to determine. It seems appropriate to assume the mean value to be one for the distribution function, $P(y)$, to be approximated as well as for the approximant, $P_{a}(y)$. A pragmatic way to determine the approximant is then the following.

We choose five $y$-points, $y_{0}, y_{1}, \ldots, y_{4}$, among them $y_{0}=0$ and $y_{1}=\mathrm{I}$, in a suitable way and require the following equalities to be fulfilled.

$$
\begin{aligned}
& \mathrm{I}-P_{a}\left(y_{j}\right)=\mathrm{I}-P\left(y_{j}\right), \\
& \int_{y_{j}}^{\infty}\left(\mathrm{I}-P_{a}(y)\right) d y=\int_{y_{j}}^{\infty}(\mathrm{I}-P(y)) d y, \\
& j=0, \mathrm{I}, \ldots, 4
\end{aligned}
$$

(The equations for $j=0$ only mean that the total probability mass and the total mean value coincide for $P_{a}(y)$ and $P(y)$. For $j=\mathrm{I}, \ldots, 4$ the equations imply that not only the distribution functions coincide in $y_{j}$ but also the parts of the mean values relating to $\left(y_{j}, \infty\right)$.)

Of course, the procedure may also be used to approximate a member of class (5) with too many terms by a member of class (5) with at most five terms. 
4. Examples ChOSEN FOR THE NUMERICAL illustration

For $P(y)$ we choose

I) the simple exponential $\mathrm{I}-e^{-y}$

II) Seal's Pareto example $\mathrm{I}-(\mathrm{I}+2 y)^{-3 / 2}$

III) a five terms exponential approximant of II by the use of $y_{0}=0, y_{1}=\mathrm{I}, y_{2}=\mathrm{Io}, y_{3}=\mathrm{IOO}, y_{4}=$ I000.

For $K(t)$ we choose
A) the Poisson choice $I-e^{-t}$
B) the Sparre Andersen choice I $-0.25 e^{-0.4 t}-0.75 e^{-2 t}$
C) the analogue of Seal's Pareto example $\mathrm{I}-(\mathrm{I}+2 t)^{-3 / 2}$
D) the five terms exponential approximant of $\mathrm{C}$, analogous to III.

All the distribution functions listed have mean values equal to one. In the case II we have

$p^{+}(x)=\mathrm{I}+x-2\left(\frac{x}{2}\right)^{3 / 2} e^{-x / 2} \int_{0}^{x / 2} y^{-\frac{1}{2}} e^{y} d y+2 i \sqrt{\pi}\left(\frac{x}{2}\right)^{3 / 2} e^{-x / 2}$

For $c$ we choose $0.90,0.95, \ldots, \mathrm{I} .25, \mathrm{I} .30,2.00$

For $u$ we choose 0 , 100, I000, I0.000

For $t$ we choose 100, 1000, 10.000, $\infty$.

We do not illustrate all the possible combinations of our choices. In particular we only illustrate the choices of $c \leqq$ I.Io for the d.f. pairs IA, IB, IIIA, IIIB and $c \geqq I .05$ for the d.f. pairs IC, ID, IIA, IIB.

In a special table, proposed by $\mathrm{Mr}$. Bohman, we also illustrate IIIA in combination with $c=0.98,0.99$, I.00, I.OI, I.02, I.03, I.04 for some values of $u$ and $t$.

5. Asymptotic Behavior of $\psi(u)$ For $u \rightarrow \infty$

If we choose III for $P(y)$ then we know that there are a strictly positive value $R$ and a constant $o<C<\mathrm{I}$ such that for $c>\mathrm{I}$

$$
\psi(u) \sim C e^{-R u}, \quad u \rightarrow \infty
$$


On the contrary if we choose II for $P(y)$ then we know that for $c>\mathrm{I}$

$$
\psi(u) \sim \frac{\mathrm{I}}{c-\mathrm{I}} \int_{u}^{\infty}[\mathrm{I}-P(y)] d y=\frac{\mathrm{I}}{c-\mathrm{I}}(\mathrm{I}+2 u)^{-\frac{1}{2}} \sim \frac{C_{1}}{\sqrt{u}}
$$

The asymptotic behavior of $\psi(u)$ for $u \rightarrow \infty$ is thus entirely different for II and III though III otherwise is a good approximant to II.

\section{Numerical methods}

The calculations are carried out in two main steps, first the calculation of $\bar{\psi}(u, z)$ from the formulas given above and then the evaluation of $\psi(u, t)$ from $\bar{\psi}(u, z)$ by a numerical inversion.

As stated earlier the formulas make use of the roots of the equation $\mathbf{I}-k(z-c s) p(s)=0$. If both the d.f. of claims and the d.f. of interclaim times are of the exponential type this equation becomes polynomial with complex coefficients. To solve it an algorithm is used, which is based on the Newton-Raphson method, generalized by $\mathrm{K}$. Nickel in "Die numerische Berechnung der Wurzeln eines Polynoms", Numerische Mathematik, I966, pp. 8o98. It must be observed that the algorithm is operating well only if the starting value is fairly good. It is therefore convenient to use the roots $r_{v}(z)(v=\mathrm{I}, 2, \ldots, n)$-obtained for a fixed value of the parameter $c$ and a certain value of the argument $z$-as the starting values when solving the equation for a succeeding value $z+\Delta z$, where $|\Delta z|$ is not too large.

If at least one of the d.f. 's involved is of the Pareto type, the equation is non-polynomial and a special generalization of the Newton-Raphson method is used. The method is described by Fröberg: "Introduction to Numerical Analysis", Addison-Wesley, I965, pp. 23-24, and makes use of the function and its first four derivatives. Even in this case a starting value has to be carefully chosen.

The inversion of $\Psi(u, z)$ into $\psi(u, t)$ is performed with a method given by Piessens in "New quadrature formulas for the numerical inversion of the Laplace transform", BIT, vol. 9, I969, pp. 35I-36I. 
The quadrature is based on 25 points in the complex plane. As pointed out by Piessens in Journal of engineering mathematics 5:I, January I97I, his method in the form used here may be expected to be successful only if the function to be inverted is regular at infinity. This condition is satisfied in the present cases.

In general the number of correct decimals are four but in most cases even five.

Some results presented here have already been published by Wikstad in Astin Bulletin VI:2, and some in a mimeographed paper by Thorin and Wikstad presented at the Conference on capitalization of risk ventures in Madison, Wisconsin, in Oct. I97I. Some of the present figures differ slightly from those earlier published due to improvements in the methods.

The computer programs used here are written in "full" FORTRAN. The calculations have been performed on a CDC 660o. The execution time is about one minute or less per table.

\section{NUMERICAL RESUlts}

The $\left(a_{v}, \alpha_{v}\right)_{1}^{5}$ in III have been found to be

\begin{tabular}{lll}
$v$ & \multicolumn{1}{c}{$a_{v}$} & \multicolumn{1}{c}{$\alpha_{v}$} \\
$\mathrm{I}$ & 0.6635948 & 3.675472 \\
2 & $0.3 \mathrm{II} 4878$ & $0.7 \mathrm{II} 6063$ \\
3 & 0.02405664 & 0.094477445 \\
4 & 0.0008425574 & 0.009322980 \\
5 & 0.00001823254 & 0.0004965620
\end{tabular}

All other results are presented in the tables I-9.

\section{CONCLUding REMARis}

Of the two authors Thorin is responsible for the sections $1-5$ and Wikstad for the sections 6-7 including the attached tables. The paper has been written as a part of the work carried out by the Swedish committee for the practical applications of the risk theory mentioned in Thorin's paper in Astin Bulletin VI: $\mathrm{I}$. The detailed derivation of the main new formulas in sections I-5 will appear in a forthcoming paper in Skandinavisk Aktuarietidskrift by Thorin. 


\section{TABLE I}

Claim d.f.: $P(y)=\mathrm{I}-e^{-y}$

Interclaim time d.f.: $K(t)=\mathrm{I}-e^{-t}$

\begin{tabular}{|c|c|c|c|c|c|c|}
\hline & $u$ & $c=0.90$ & 0.95 & 1.00 & I.05 & I. IO \\
\hline \multirow[t]{2}{*}{$T=\mathrm{I} 00$} & o & .97908 & .96398 & .94360 & .91852 & .88997 \\
\hline & IOO & .00000 & .00000 & .00000 & .00000 & .00000 \\
\hline \multirow[t]{3}{*}{$T=1000$} & o & .99976 & .99695 & .98210 & .94939 & .90882 \\
\hline & IOO & .57207 & .187 I 5 & .02749 & .00186 & .00007 \\
\hline & I 000 & .00000 & .00000 & .00000 & .00000 & .00000 \\
\hline \multirow[t]{4}{*}{$T=\mathrm{I} 0000$} & o & I.00000 & .99997 & .99433 & .95235 & .90906 \\
\hline & IOO & I.00000 & .99933 & .47622 & $.008 I_{4}$ & .00010 \\
\hline & I 000 & .52380 & $.0003 I$ & .00000 & .00000 & .00000 \\
\hline & IOOOO & .00000 & .00000 & .00000 & .00000 & .00000 \\
\hline \multirow[t]{4}{*}{$T=\infty$} & $\mathrm{O}$ & I.00000 & I.00000 & I.00000 & .95238 & .90909 \\
\hline & IOO & I.00000 & I. .00000 & I.00000 & $.008 \mathrm{I} 4$ & .00010 \\
\hline & I 000 & I.00000 & I.OOOOO & I.00000 & .00000 & .00000 \\
\hline & I0000 & I.00000 & 1.00000 & 1.00000 & .00000 & .00000 \\
\hline
\end{tabular}

TABLE 2

Claim d.f.: $P(y)=\mathrm{I}-e^{-y}$

Interclaim time d.f.: $K(t)=\mathrm{I}-0.25 e^{-0.4 t}-0.75 e^{-2 t}$

\begin{tabular}{|c|c|c|c|c|c|c|}
\hline & $u$ & $c=0.90$ & 0.95 & I.OO & I.05 & I. IO \\
\hline \multirow[t]{3}{*}{$T=\mathbf{I} 00$} & o & .97917 & .96944 & .95737 & .943 I6 & $.927 \mathrm{I} 4$ \\
\hline & IOO & $.0000 I$ & $.0000 \mathrm{I}$ & .00000 & .00000 & .00000 \\
\hline & IOOO & .00000 & .00000 & .00000 & .00000 & .00000 \\
\hline \multirow[t]{3}{*}{$T=\mathbf{1 0 0 0}$} & o & .99932 & $.996 \mathrm{I}_{4}$ & .98646 & .96862 & $.9457^{8}$ \\
\hline & 100 & $.599 I I$ & .29176 & .09321 & .01962 & .00290 \\
\hline & I 000 & .00000 & .00000 & .00000 & .00000 & .00000 \\
\hline \multirow[t]{4}{*}{$T=\mathrm{I} 0000$} & 0 & I.00000 & .99996 & $.9957 \mathbf{I}$ & .97234 & .94646 \\
\hline & roo & I.00000 & .99543 & .58994 & .06 IIO & $.0044^{8}$ \\
\hline & Iooo & .53359 & .00539 & .00000 & .00000 & .00000 \\
\hline & IOOOO & .00000 & .00000 & .00000 & .00000 & .00000 \\
\hline \multirow[t]{4}{*}{$T=\infty$} & o & I.00000 & I. 00000 & 1.00000 & .97237 & .94648 \\
\hline & IOO & I.00000 & I.00000 & I.00000 & $.06 \times 39$ & .00448 \\
\hline & IOOO & I.00000 & I.00000 & I.00000 & .00000 & .00000 \\
\hline & I 0000 & I.00000 & I.00000 & I.00000 & .00000 & .00000 \\
\hline
\end{tabular}


TABLE 3

\begin{tabular}{|c|c|c|c|c|c|c|c|}
\hline & $\begin{array}{l}\operatorname{laim} d \\
\text { atercla }\end{array}$ & $\begin{array}{l}P(y)= \\
\text { time d.f. }\end{array}$ & $\begin{array}{l}-e^{-y} \\
K(t)=\end{array}$ & $I-($ & $+2 t)$ & & \\
\hline & $u$ & $c=\mathrm{I} .05$ & I.1O & I.I 5 & 1.20 & $\mathrm{I} .25$ & I. 30 \\
\hline$=100$ & o & $.98 \mathbf{1} 5^{8}$ & .97739 & .97247 & .96680 & .96036 & .95317 \\
\hline & I0O & $.002 \mathrm{I}_{4}$ & .00125 & .00072 & $.004^{\circ}$ & .00022 & .00012 \\
\hline & 1000 & .00000 & .00000 & .00000 & .00000 & .00000 & .00000 \\
\hline$=1000$ & o & .99460 & $.99 \times 29$ & .98653 & .98020 & .97242 & .96347 \\
\hline & 100 & .47194 & .32876 & .20382 &. $\operatorname{III} 45$ & $.0537^{2}$ & .02304 \\
\hline & IOOO & .00000 & .00000 & .00000 & .00000 & .00000 & .00000 \\
\hline$\Gamma=\mathbf{1} 0000$ & o & .99782 & .99439 & .98872 & $.98 I_{43}$ & .97299 & $.9637^{\circ}$ \\
\hline & IOO & $.7952 \mathrm{I}$ & .56403 & $.3203 \mathrm{I}$ &. $\mathrm{I} 535^{\circ}$ & $.0654^{6}$ & .02560 \\
\hline & 1000 & .02222 & .00076 & $.0000 \mathrm{I}$ & .00000 & .00000 & .00000 \\
\hline & 10000 & .00000 & .00000 & .00000 & .00000 & .00000 & .00000 \\
\hline$T=\infty$ & 0 & .99854 & .99460 & .98876 & $.98 \mathrm{I} 45$ & .97301 & .96372 \\
\hline & 100 & .86266 & $.5797^{6}$ & .32132 & .15352 & .06546 & .02560 \\
\hline & 1000 & .23126 & $.0045^{\circ}$ & .00001 & .00000 & .00000 & .00000 \\
\hline & 10000 & .00000 & .00000 & .00000 & .00000 & .00000 & .00000 \\
\hline
\end{tabular}

TABLE 4

Claim d.f.: $P(y)=\mathrm{I}-e^{-y}$

Interclaim time d.f.: $K(t)=\sum_{1}^{s} a_{v}\left(\mathrm{I}-e^{-\alpha_{v} y}\right)$

\begin{tabular}{|c|c|c|c|c|c|c|c|}
\hline & $u$ & $c=\mathbf{I} .05$ & I.1O & I.I 5 & 1.20 & 1.25 & I.30 \\
\hline \multirow[t]{3}{*}{$T=\mathrm{I00}$} & o & $.9809 \mathrm{I}$ & .97664 & .97163 & .96586 & .95932 & .95200 \\
\hline & 100 & .00245 & .00181 & .00126 & .00083 & $.0005 \mathrm{I}$ & $.0003^{\circ}$ \\
\hline & 1000 & .00000 & .00000 & .00000 & .00000 & .00000 & .00000 \\
\hline \multirow[t]{3}{*}{$T=\mathrm{I} 000$} & o & .99445 & .99096 & .98590 & .97920 & .97104 & .96176 \\
\hline & 100 & .46060 & .31499 & .19036 & .10093 & $.047^{\circ} 5$ & .01952 \\
\hline & 1000 & .00000 & .00000 & .00000 & .00000 & .00000 & .00000 \\
\hline \multirow[t]{4}{*}{$T=$ I0000 } & o & .99769 & .99403 & .98805 & .98036 & .97154 & .96193 \\
\hline & IOO & .784 OI & $.544^{\circ} \mathrm{I}$ & .29920 & . 13780 & $.0565 \mathrm{I}$ & .02139 \\
\hline & 1000 & .01832 & .00053 & .00000 & .00000 & .00000 & .00000 \\
\hline & 10000 & .00000 & .00000 & .00000 & .00000 & .00000 & .00000 \\
\hline \multirow[t]{4}{*}{$T=\infty$} & 0 & $.9984 \mathrm{I}$ & .99422 & .98808 & .98038 & .97156 & .96194 \\
\hline & 100 & .85126 & .55805 & .29999 & .13781 & $.0565 I$ & .02139 \\
\hline & 1000 & $.2027 \mathrm{I}$ & .00309 & $.0000 \mathrm{I}$ & .00000 & .00000 & .00000 \\
\hline & IOOOO & .00000 & .00000 & .00000 & .00000 & .00000 & .00000 \\
\hline
\end{tabular}


TABLE 5

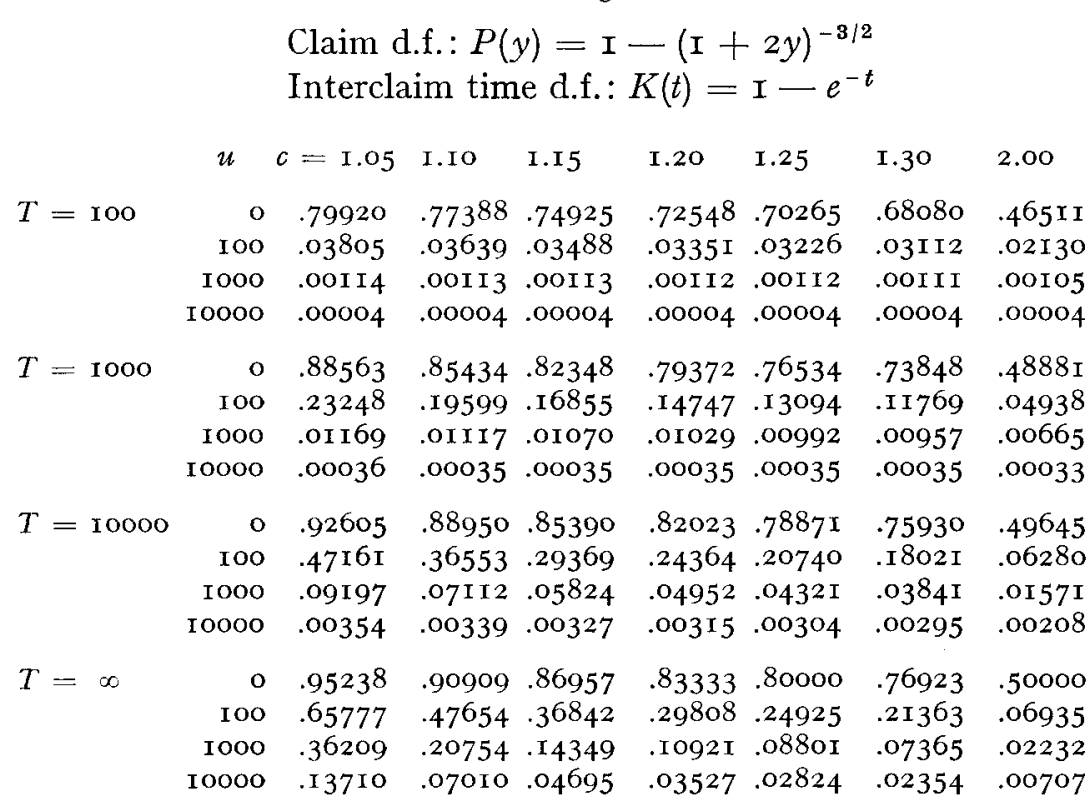

TABLE 6

\begin{tabular}{|c|c|c|c|c|c|c|c|c|}
\hline \multirow[b]{2}{*}{$T=\mathbf{I} 00$} & $u$ & $c=1.05$ & I.IO & I.I 5 & $\mathrm{I} .20$ & 1.25 & I. 30 & 2.00 \\
\hline & $\begin{array}{r}0 \\
100 \\
1000 \\
\text { I0000 }\end{array}$ & $\begin{array}{l}.85 \text { I } 4 \text { I } \\
.04057 \\
.00115 \\
.00004\end{array}$ & $\begin{array}{l}.83197 \\
.03870 \\
.00114 \\
.00004\end{array}$ & $\begin{array}{l}.81267 \\
.03702 \\
.00114 \\
.00004\end{array}$ & $\begin{array}{l}.79366 \\
.03549 \\
.00113 \\
.00004\end{array}$ & $\begin{array}{l}.77505 \\
.034 \mathrm{II} \\
.00 \mathrm{II} 3 \\
.00004\end{array}$ & $\begin{array}{l}.75692 \\
.03284 \\
.00112 \\
.00004\end{array}$ & $\begin{array}{l}.56026 \\
.02219 \\
.00106 \\
.00004\end{array}$ \\
\hline$T=1000$ & $\begin{array}{r}0 \\
100 \\
1000 \\
10000\end{array}$ & $\begin{array}{l}.91698 \\
.2455^{\circ} \\
.01181 \\
.00036\end{array}$ & $\begin{array}{l}.89355 \\
.20648 \\
.01127 \\
.00035\end{array}$ & $\begin{array}{l}.86994 \\
.17702 \\
.01079 \\
.00035\end{array}$ & $\begin{array}{l}.84668 \\
.15439 \\
.01037 \\
.00035\end{array}$ & $\begin{array}{l}.82408 \\
.13667 \\
.00999 \\
.00035\end{array}$ & $\begin{array}{l}.80230 \\
.1225 \mathrm{I} \\
.00964 \\
.00035\end{array}$ & $\begin{array}{l}.58004 \\
.05065 \\
.00668 \\
.00033\end{array}$ \\
\hline$T=10000$ & $\begin{array}{r}0 \\
100 \\
1000 \\
\text { 10000 }\end{array}$ & $\begin{array}{l}.94674 \\
.48584 \\
.09345 \\
.00355\end{array}$ & $\begin{array}{l}.91964 \\
.37749 \\
.07197 \\
.0034^{\circ}\end{array}$ & $\begin{array}{l}.89266 \\
.30329 \\
.05879 \\
.00327\end{array}$ & $\begin{array}{l}.86663 \\
.25 \mathrm{I} 34 \\
.04990 \\
.003 \mathrm{I} 5\end{array}$ & $\begin{array}{l}.84 \mathrm{I} 78 \\
.2 \mathrm{I} 367 \\
.04348 \\
.00305\end{array}$ & $\begin{array}{l}.8 \mathrm{I} 8 \mathrm{I} 7 \\
.18540 \\
.03862 \\
.00295\end{array}$ & $\begin{array}{l}.58633 \\
.06408 \\
.01575 \\
.00208\end{array}$ \\
\hline$T=\infty$ & $\begin{array}{r}0 \\
100 \\
1000 \\
10000\end{array}$ & $\begin{array}{l}.96578 \\
.66784 \\
.36467 \\
.13729\end{array}$ & $\begin{array}{l}.93393 \\
.48682 \\
.2088 \mathrm{I} \\
.07016\end{array}$ & $\begin{array}{l}.90420 \\
.37720 \\
.14421 \\
.04697\end{array}$ & $\begin{array}{l}.87637 \\
.30533 \\
.10967 \\
.03528\end{array}$ & $\begin{array}{l}.85025 \\
.25524 \\
.08834 \\
.02825\end{array}$ & $\begin{array}{l}.82569 \\
.21865 \\
.07390 \\
.02355\end{array}$ & $\begin{array}{l}.58925 \\
.07062 \\
.02236 \\
.00707\end{array}$ \\
\hline
\end{tabular}




\section{TABLE 7}

\begin{tabular}{|c|c|c|c|c|c|c|}
\hline & \multicolumn{6}{|c|}{$\begin{array}{l}\text { Interclaim time d.f.: } K(t)=I-e^{-t} \\
\text { (See also Table } 9 \text { ) }\end{array}$} \\
\hline & $u$ & $c=0.90$ & 0.95 & 1.00 & I.05 & I. IO \\
\hline$T=\mathrm{I} 00$ & $\begin{array}{r}0 \\
100 \\
1000 \\
10000\end{array}$ & $\begin{array}{l}.87986 \\
.04172 \\
.00113 \\
.00001\end{array}$ & $\begin{array}{l}.85466 \\
.03992 \\
.00113 \\
.00001\end{array}$ & $\begin{array}{l}.82900 \\
.03835 \\
.00113 \\
.00001\end{array}$ & $\begin{array}{l}.80331 \\
.03694 \\
.00112 \\
.00001\end{array}$ & $\begin{array}{l}.77794 \\
.03569 \\
.00112 \\
.00001\end{array}$ \\
\hline$T=\mathrm{I} 000$ & $\begin{array}{r}0 \\
100 \\
1000 \\
10000\end{array}$ & $\begin{array}{l}.9694 \mathrm{I} \\
.4345 \mathrm{I} \\
.0124 \mathrm{I} \\
.00014\end{array}$ & $\begin{array}{l}.94596 \\
.34602 \\
.01202 \\
.00014\end{array}$ & $\begin{array}{r}.91786 \\
.28170 \\
.01169 \\
.00013\end{array}$ & $\begin{array}{l}.88742 \\
.23479 \\
.01141 \\
.00013\end{array}$ & $\begin{array}{l}.85634 \\
.19972 \\
.01118 \\
.00013\end{array}$ \\
\hline$T=$ I0000 & $\begin{array}{r}0 \\
100 \\
1000 \\
10000\end{array}$ & $\begin{array}{l}.99837 \\
.96048 \\
.37068 \\
.00251\end{array}$ & $\begin{array}{l}.98754 \\
.81950 \\
.19754 \\
.00208\end{array}$ & $\begin{array}{r}.96167 \\
.62563 \\
.12747 \\
.00176\end{array}$ & $\begin{array}{l}.92684 \\
.46802 \\
.09938 \\
.00152\end{array}$ & $\begin{array}{l}.89043 \\
.36353 \\
.08487 \\
.00133\end{array}$ \\
\hline$T=\infty$ & $\begin{array}{r}0 \\
100 \\
1000 \\
10000\end{array}$ & $\begin{array}{l}\text { I.00000 } \\
\text { I.00000 } \\
\text { I.00000 } \\
\text { I.00000 }\end{array}$ & $\begin{array}{l}\text { I. } 00000 \\
\text { I.00000 } \\
\text { I.00000 } \\
\text { I.00000 }\end{array}$ & $\begin{array}{l}\text { I.00000 } \\
\text { I.00000 } \\
\text { I.00000 } \\
\text { I.00000 }\end{array}$ & $\begin{array}{l}.95238 \\
.65168 \\
.35372 \\
.02890\end{array}$ & $\begin{array}{l}.90909 \\
.47017 \\
.20301 \\
.00801\end{array}$ \\
\hline
\end{tabular}

\section{Table 8}

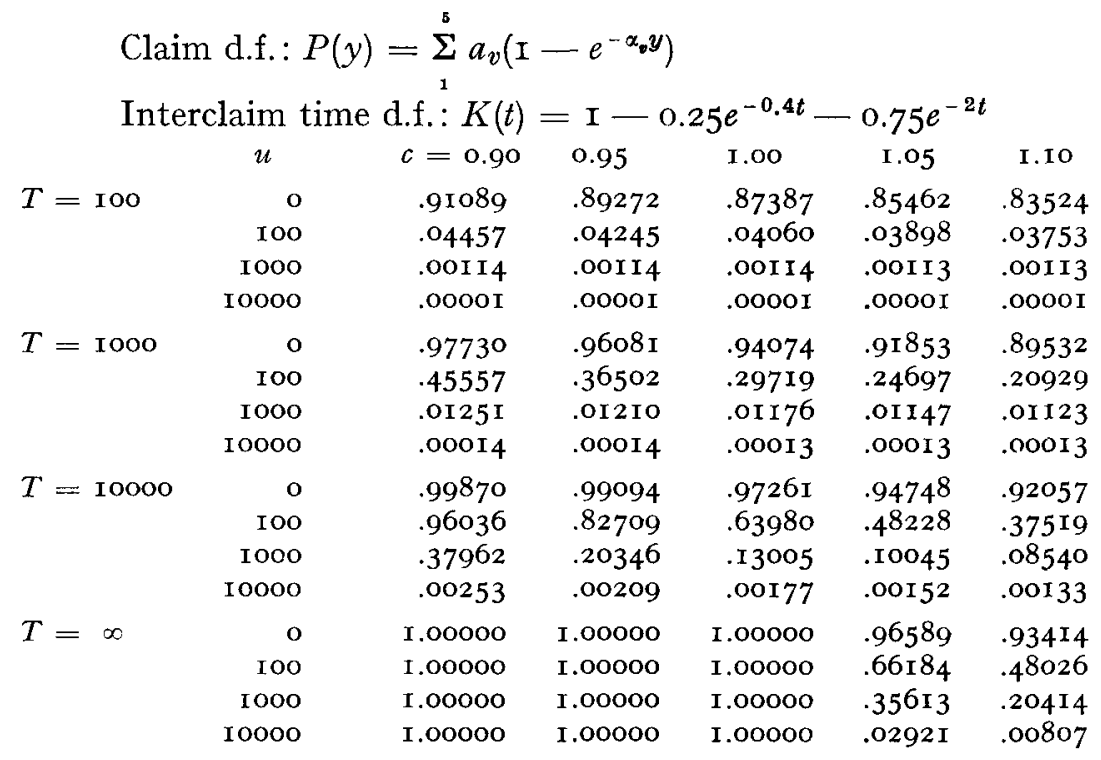


TABLE 9

Claim d.f.: $P(y)=\sum^{s} a_{v}\left(\mathrm{I}-e^{-\alpha_{v} y}\right)$

Interclaim time d.f.: $K(t)=\mathrm{I}-e^{-t}$

(See also Table 7)

\begin{tabular}{|c|c|c|c|c|c|c|c|}
\hline$T$ & $c=0.98$ & 0.99 & 1.00 & I.OI & I.02 & I.03 & $\mathrm{I} .04$ \\
\hline $5^{00}$ & .00576 & .00575 & .00573 & .00572 & $.0057 \mathrm{I}$ & $.0057^{\circ}$ & .00569 \\
\hline 1000 & $.0 \mathrm{II} 8 \mathrm{I}$ & .01175 & .01169 & .01163 & .01557 &. $\mathrm{OII} 5^{2}$ & .01147 \\
\hline 2000 & $.024^{82}$ & $.0244^{8}$ & .02417 & .02388 & $.0236 \mathrm{I}$ & .02335 & $.023 \mathrm{II}$ \\
\hline$\infty$ & I.00000 & 1.00000 & 1.00000 & .75745 & .59904 & .49013 & $.4 \mathrm{I} I 93$ \\
\hline \multicolumn{8}{|l|}{$u=\mathrm{I} 0000$} \\
\hline$T$ & $c=0.98$ & 0.99 & I.OO & I.OI & 1.02 & I.03 & I. 04 \\
\hline $5^{0000}$ & .02008 & $.0175 \mathbf{I}$ & $.0 \times 534$ & $.0135^{\circ}$ & .01194 & $.0106 \mathrm{I}$ & .00946 \\
\hline I 00000 & .06379 & .05089 & .04090 & .033 I I & .02701 & .02220 & .01838 \\
\hline 200000 & .19062 & $.13^{802}$ & .09998 & .07276 & .05339 & .03963 & .02984 \\
\hline$\infty$ & 1.00000 & I.00000 & I.00000 & .31822 & .13727 & .07226 & .04357 \\
\hline \multicolumn{8}{|c|}{$u=\mathrm{I} 00000$} \\
\hline$T$ & $c=0.9^{8}$ & 0.99 & I.OO & I.OI & I. 02 & 1.03 & I.04 \\
\hline 5000000 & .52496 & .06436 & .00160 & $.0000 \mathrm{I}$ & .00000 & .00000 & .00000 \\
\hline I 0000000 & .99557 & .556 I 5 & .01994 & .00004 & .00000 & .00000 & .00000 \\
\hline 20000000 & .99985 & .97234 & .09227 & .00005 & .00000 & .00000 & .00000 \\
\hline$\infty$ & I.00000 & I.00000 & I.00000 & .00006 & .00000 & .00000 & .00000 \\
\hline
\end{tabular}

